\title{
PERFURAÇÃO ESPONTÂNEA DE COLÉDOCO EM ADOLESCENTE
}

\author{
SPONTANEOUS PERFORATION OF THE COMMON DUCT IN A TEENAGER
}

\author{
Francisco Edilson Leite Pinto Júnior, TCBC-RN ${ }^{1}$ \\ Ariano José Freitas de Oliveira, RCBC-RN ${ }^{2}$ \\ Andrea Fernandes de Oliveira, RCBC-RN ${ }^{2}$
}

\section{INTRODUÇÃO}

A perfuração espontânea da árvore biliar é uma rara causa de peritonite biliar em adultos jovens, mesmo na presença de cálculos biliares. Contudo, encontra-se em segundo lugar como causa cirúrgica de icterícia no período neonatal, logo após a atresia de vias biliares ${ }^{1}$.

O nosso objetivo é relatar o caso de um paciente portador de retocolite ulcerativa associada com tumor de cabeça do pâncreas, que apresentou perfuração espontânea de colédoco.

\section{RELATO DO CASO}

Um paciente do sexo masculino com 18 anos de idade, portador de retocolite ulcerativa há cinco anos, deu entrada no serviço de cirurgia geral com história de icterícia progressiva, há dois meses, associada com náuseas e vômitos. Encontrava-se com estado geral comprometido e fazendo uso de sulfassalazina, prednisona e ácido ursodesoxicólico. Foi submetido a uma tomografia computadorizada de abdome que evidenciou processo expansivo sólido na cabeça do pâncreas, de aproximadamente $8 \mathrm{~cm}$ de diâmetro, e múltiplas metástases hepáticas. Vinte e quatro horas após o internamento, passou a apresentar dor abdominal súbita, de forte intensidade, associada com vômitos e parada de eliminação de gases e fezes. No exame físico, o abdome encontrava-se com sinais de irritação peritoneal. Optou-se pela realização de uma laparotomia exploradora, sendo constatada uma tumoração na cabeça do pâncreas, múltiplas metástases hepáticas, quadro de coleperitôneo e perfuração do colédoco distal em sua parede anterior, porém sem alterações na sua espessura. Foi realizada drenagem externa com tubo em $\mathrm{T}$ (Kehr), atra- vés do local da perfuração e biópsia hepática. No pós-operatório imediato não houve regressão da icterícia, entretanto, o paciente mantinha-se estável. Recebeu alta hospitalar no $13^{\circ}$ dia de pós-operatório e evoluiu para óbito após trinta dias. $\mathrm{O}$ resultado anatomopatológico revelou carcinoma indiferenciado metastático.

\section{DISCUSSÃO}

A perfuração espontânea do sistema biliar extra-hepático é extremamente rara, com exceção da ruptura da vesícula que ocorre em $3 \%$ a $10 \%$ dos casos de colecistite aguda $^{1,2}$. Essa afecção acontece principalmente entre a primeira semana e os primeiros três meses de idade ${ }^{3}$.

Após a primeira descrição feita por Freeland, em 1882, vários casos foram publicados na literatura. Porém, a maioria estava associada a obstrução biliar. Spira, relatou onze casos de perfuração do colédoco em adultos e somente em um deles não havia cálculos ou obstrução ${ }^{4}$.

A fisiopatologia desse processo pode ser explicada pela presença de anomalias congênitas ou doenças obstrutivas adquiridas, tais como: tumor, cálculo impactado, espasmo do esfíncter de Oddi, infecção ou infarto intramural, ruptura de um divertículo ou cisto do trato biliar, regurgitação do suco pancreático ou friabilidade do trato biliar devido à operação prévia que culminam com o aumento da pressão intraductal e estase biliar, com consequiente ruptura não traumática da árvore biliar extra-hepática ${ }^{2}$.

O local preferencial é a face anterior do ducto hepático, sendo rara a perfuração posterior ${ }^{4}$. A apresentação clínica pode ser insidiosa ou aguda, sendo a primeira mais comum e caracterizada por icterícia progressiva, ascite e acolia fecal. A forma aguda é mais rara e pode apre-

1. Professor Assistente da Disciplina de Técnica Operatória-Cirurgia Experimental e Coordenador da Residência de Cirurgia Geral da UFRN. Mestre em Cirurgia pela UFPE.

2. Residente de Cirurgia Geral da UFRN

Recebido em 31/3/99

Aceito para publicação 17/11/99

Trabalho realizado na Disciplina de Técnica Operatória e Cirurgia Experimental do Departamento de Cirurgia da Universidade Federal do Rio Grande do Norte - UFRN. 
sentar-se com distensão abdominal, febre, vômitos e sinais de peritonite fulminante ${ }^{5}$.

A mortalidade permanece elevada, principalmente quando há retardo no seu diagnóstico e não se estabelece o tratamento cirúrgico adequado. Encontra-se em torno de $50 \%$ no adulto e $25 \%$ na criança ${ }^{2}$.

No caso ora relatado o paciente era jovem e havia uma condição obstrutiva, tumor de cabeça de pâncreas, associada à doença inflamatória intestinal, que evoluiu com quadro de peritonite. Durante a operação foi constatada a ruptura não traumática do colédoco. O trata- mento escolhido foi a descompressão biliar externa com dreno de Kehr pelo local da perfuração.

Embora não tendo encontrado na literatura a associação da doença inflamatória intestinal com a neoplasia de cabeça do pâncreas, pode-se sugerir que o uso prolongado de drogas imunossupressoras, feito pelo paciente para o tratamento da retocolite ulcerativa, tenha contribuído para o aparecimento do tumor pancreático e, desta forma, predispondo a perfuração do colédoco.

Apesar da raridade, a perfuração da árvore biliar deve ser lembrada nos casos de peritonite ${ }^{1}$.

\begin{abstract}
Spontaneous perforation of the common bile duct is rare. It happens predominantly in children and it is related to obstructive disease of the biliary tract. We present a case of an 18 year-old male patient, with ulcerative rectocolitis associated with malignant tumor of the head of pancreas. The patient developed an acute abdomen syndrome and laparotomy, a spontaneous perforation of common bile duct was evidenced. The authors make a revision of the clinical aspects of that pathology.
\end{abstract}

Key Words: Choledochus; Sponteneous perforation.

\section{REFERÊNCIAS}

1. Campo MD, Giguens M - Perfuracion espontánea del colédoco el ninõ. Cir Urug 1994; 64(1) 73-75.

2. Spigland N, Greco R, Rosenfeld D - Spontaneous biliary perforation: does external drainage constitute adequate therapy ? J Pedriat Surg 1996; 31(6): 782-784.

3. Lilly JR, Weinraub WH, Altmann RP - Spontaneous perforation of the extrahepatic ducts and bile peritonitis in infancy. Surgery 1974; 75(5): 664-673.

4. Spira IA - Spontaneous rupture of the common bile duct. Ann Surg 1976; 183(4): 433-435.
5. Nomura T, Nikkuni K, Kato H, Yoshikawa T et al - Bile peritonitis due to a spontaneous perforation of the common bile duct. Surg Today 1996; 26(10): 822-823.

\section{ENDEREÇO PARA CORRESPONDÊNCIA}

Dr. Francisco Edilson Leite Pinto Junior

Av Brigadeiro Gomes Ribeiro, 1025

59056-520 - Natal-RN

E-Mail: edilsonpinto@uol.com.br 